\title{
Chapter 80 \\ Competitiveness of Circumpolar Countries in the Digital Environment
}

\author{
V. P. Samarina, A. V. Samarin, and T. P. Skufina
}

\begin{abstract}
The paper is devoted to solving the fundamental problem of the countries which Arctic territories are rich in natural resources. This is a contradiction between the necessity of forming an innovative, digital model of the economy and the reality of the extractive economy. The aim of the research is to assess the competitiveness of circumpolar countries in the digital environment. The authors have revealed several deterrents holding back development of projects in circumpolar countries that are not related to the extraction and primary processing of natural resources; assessed the subjective prerequisites for using a digital product to solve the production and infrastructure problems of the circumpolar countries; compared circumpolar countries in terms of number of student-one of the factors of competitiveness in the digital environment; rated the circumpolar countries in terms of competitiveness in the digital environment.
\end{abstract}

\subsection{Introduction}

The developing crisis caused by the pandemic coronavirus is forcing to look for new ways of economic development. The crisis has already largely changed the economy of most countries of the world and changes continue to take place. The crisis has affected also circumpolar countries which have Arctic territories. Arctic territories are usually rich in minerals and this determines the development of the extractive-type economy.

Circumpolar countries run into such fundamental problem as the contradiction between the problem of building an innovative, digital economical model and the

\footnotetext{
V. P. Samarina (囚) • T. P. Skufina

Federal Research Center "Kola Science Center of the Russian Academy of Sciences", Luzin Institute for Economic Studies, Fersman St., 14, 1842090 Apatity, Russia
}

\footnotetext{
A. V. Samarin

Belgorod State National Research University (Stary Oskol Branch), Solnechny st., 18, 309502 Stary Oskol, Russia

(C) The Author(s), under exclusive license to Springer Nature Singapore Pte Ltd. 2021

D. B. Solovev et al. (eds.), Proceeding of the International Science and Technology

Conference "FarEastCon 2020", Smart Innovation, Systems and Technologies 227,

https://doi.org/10.1007/978-981-16-0953-4_80
} 
reality of the extractive-type economy. Recently, foreign researchers of the circumpolar countries have been increasingly referring to so-called notorious curse of natural resources [1-3]. This is a situation in which the territories, rich in natural resources, demonstrate lower economic and social indicators than the areas having not large natural resources. With regard to circumpolar countries, one more very important problem is fixed - there are several factors constraining the development of projects in the Arctic territories, not related to mining and primary processing of natural resources. The authors have already noted these trends in their papers [4-6].

At the same time, more and more extractive and processing enterprises start to operate in the digital environment. According to researchers' opinions, digital technologies raise labor productivity and safety and improve the environment [7-9]. In addition, the ability of business to adapt to external changes improves and this fact increases antirecessionary stability [10-12].

The aim of the research is to assess the competitiveness of circumpolar countries in the digital environment.

The objectives of the research are the following:

- to reveal factors constraining the development of projects not related to mining and primary processing of natural resources in circumpolar countries;

- to assess subjective prerequisites for the use of digital products in order to solve production and infrastructure problems of the circumpolar countries;

- to compare the circumpolar countries by the number of students-one of the factors of competitiveness in the digital environment;

- to determine the rating of the circumpolar countries for competitiveness in the digital environment.

\subsection{Materials and Methods}

The object of research is eight circumpolar countries which have Arctic territories.

The subject of the research is the competitiveness of the circumpolar countries in the digital environment.

To solve specific problems of the research, the methods of comparison and matching of information in the circumpolar countries were used. The method of summarizing the information obtained from various literature sources was used as well. The comparison of circumpolar countries was made in terms of student numbers, as one of the factors of competitiveness in the digital environment. To do this, the number of students has been calculated (students enrolled in higher education programs in educational institutions of higher and postgraduate education) per 1000 people. The calculations were carried out by the authors on the materials of the Internet portal Infotables. Ru [13]. The comparisons have been made for the circumpolar countries with Arctic territories.

In order to determine the ranking of the countries with Arctic territories in terms of competitiveness in the digital environment, the authors used the data of the Swiss 
business school IMD [14]. For the formation of the IMD World Digital Competitiveness Ranking, 50 criteria are used. A total of 30 criteria are based on statistical data, and the rest ones are based on survey results. The criteria characterize the three components of the rating: "Knowledge" (quality of training, education and science), "Technologies" (regulatory surroundings, financial capital in the IT industry, and state of Internet and communication technologies) and "Future willingness" (level of readiness to use digital transformation).

\subsection{Results and Discussion}

\subsubsection{Deterrents for the Development of Projects not Related to the Extraction and Primary Processing of Natural Resources in Circumpolar Countries}

It is rather difficult to carry out economic activities in the high Arctic [15-17]. Having studied the features of economic activity in the Arctic territories of the circumpolar countries, we have revealed several deterrents for the development of projects not related to the extraction and primary processing of natural resources. Among them there are deterrents which, in varying degrees inherent to all Arctic areas. We have called them objective factors. Among these are:

- extreme climatic conditions;

- remoteness from administrative and financial centers;

- high cost of production;

- direct dependence on financing from the Federal budget;

- not well-developed industrial and transport infrastructure;

- small size of the population;

- high vulnerability of the natural environment.

Another group of the deterrents linked to poor governance of the Russian Arctic's territories. We have called these factors subjective. They include:

- lack of coordination of Federal and regional authorities activities with organizations realizing projects in the field;

- fragmentary and not systematic solution to the problems of realization projects concerning digital product implementation;

- lack of reasoning of some projects from an engineering and operational points of view;

- lack of modern domestic equipment capable of operating in Arctic conditions;

- insufficient number of management personnel capable of managing implementation and working out of digital projects in difficult conditions;

- shortage of skilled labor force and its low quality. 
Thus, we can see that there are lots of objective and subjective factors for the development of the circumpolar countries' Arctic territories. These deterrents are complex and various.

Under the circumstances, the introduction of digital technologies could be the problem-solving.

\subsubsection{Subjective Prerequisites for the Use of Digital Products to Solve the Circumpolar Countries' Production and Infrastructure Problems}

In a digital economy, the result of the realization of intellectual potential and the result of the work become "digital product" as a special one. It has fundamentally new and useful properties. This product is recorded in a digital code [18-20]. Digital products also include textual, graphical and other information meant for selling: software, e-books, scripts, video tutorials, etc. It is important to point out the dialectical nature of this particular product. On the one hand, like any product, it is meant for selling, exchange or other forms of commodity relations. Thus, its circulation involves making a profit or recovery of expenses. On the other hand, "digital product" serves as a means of self-expression and can be provided free of charge [21-23].

Among the subjective prerequisites for using digital products to solve the circumpolar countries' production and infrastructure problems, we highlight the following prerequisites:

1. High added cost of the results of digital products implementation. According to experts' opinions, the average sectoral ratio of final products and raw materials prices is $3: 1$. The ratio of the ultimate digital product price and its creation cost may be 10,000:1 and more [24]. This is due to the fact that the digital product added cost is created by its developer's intellectual potential, i.e., the renewable and growing resource that is not always appreciated, and, accordingly is not well-paid $[25,26]$. Thus, such digital products as an innovative technology, product or service can be an actualized result of the intellectual potential use. This will contribute to high cost-efficiency of production problem-solving and solution of the problems in the circumpolar countries' infrastructure.

2. The increasing demand for digital products. Spread world crisis has revealed the inability of the economy focused on the extraction, primary processing and export of raw materials, to withstand external actions. The digitalization of the economy will promote the Arctic territories' way out of the crisis both with minimal losses, and with acquired development potential. It will reduce crisis vulnerability of industrial and infrastructure projects in future as well.

3. The multiplicative effect of the digital product implementation. The output of innovative digital products and services is often accompanied by the increase of the conjugate production in technologically interrelated branches of production. The positive effect of one project realization is superimposed on the effect of 
another project and greatly intensifies at the same time. Thus, it can be seen the reflection of emergent properties of socio-economic systems, which manifest themselves through the increase. The result is the manifestation of positive multiplicative effect of digital products introduction. The results are manifested not only in individual circumpolar countries, but in the Arctic as a whole.

\subsubsection{The Number of Students in Circumpolar Countries as a Factor of a Country's Competitiveness in the Digital Environment}

The basis for the development of the digital environment, among other things, is the existing system of higher education. This system provides all sectors of a country's economy with diplomaed specialists, thereby promoting the creation of conditions for digitalization. As of 2018, higher education in Russia can be obtained at 607 state and 358 non-state universities. That is, the number of higher education institutions exceeds 1000. Since 1990, their number has doubled. The number of students over the same period increased to $68 \%$ : 4.7 million people in 2018 compared with 2.8 million in 1990.

It is of interest to determine Russia's rating among circumpolar countries by the number of students (Fig. 80.1).

The analysis shows that the number of students in Russia exceeds some economically developed countries' indices. Among the eight circumpolar countries, Russia takes 4th place in the number of students per 1000 population. This is a favorable but insufficient factor for increasing the country's competitiveness in the digital environment.

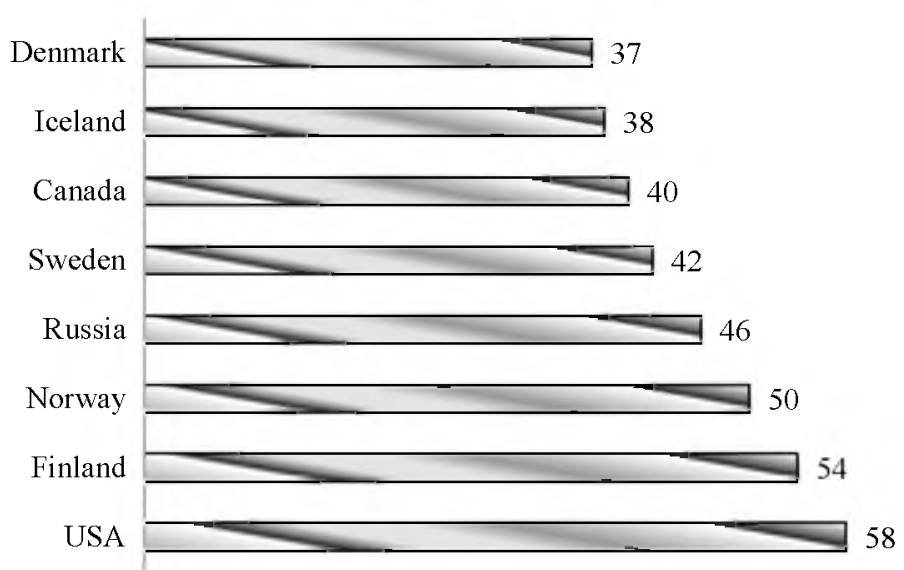

Fig. 80.1 Number of students per 1 thousand people of circumpolar countries' population (The authors' calculations based on the materials of the Internet portal Infotables Ru [13]) 


\subsubsection{Circumpolar Countries' Digital Competitiveness Ranking}

In the context of the digitalization of the economy, a country's competitiveness in the digital environment is of great importance. In order to determine Russia's rating in accordance with this index among the countries with Arctic territories, we use the data of the Swiss business school IMD World Digital Competitiveness Ranking [14].

For the formation of the IMD World Digital Competitiveness Ranking, 50 criteria are used. Thirty ones are based on statistical data, and the rest are based on survey results. The criteria characterize three components of the rating: "Knowledge" (quality of training, education and science), "Technologies" (regulatory surroundings, financial capital in IT industry, and state of Internet and communication technologies) and "Future willingness" (level of readiness to use digital transformation).

Circumpolar countries' Digital Competitiveness Ranking is shown in Fig. 80.2.

The competitiveness rating in the digital environment in 2019 was distributed in the following way:

- USA-1st place among circumpolar countries and 1st place in the world;

- Sweden -2nd place among the circumpolar countries and 3rd place in the world;

- Denmark - 3rd place among the circumpolar countries and 4th place in the world;

- Finland - 4th place among circumpolar countries and 7th place in the world;

- Norway -5th among circumpolar countries and 9th in the world;

- Canada -6th among circumpolar countries and 11th in the world;

- Iceland-7th place among the circumpolar countries and 27th place in the world;

- Russia-8th place among the circumpolar countries and 38th place in the world.

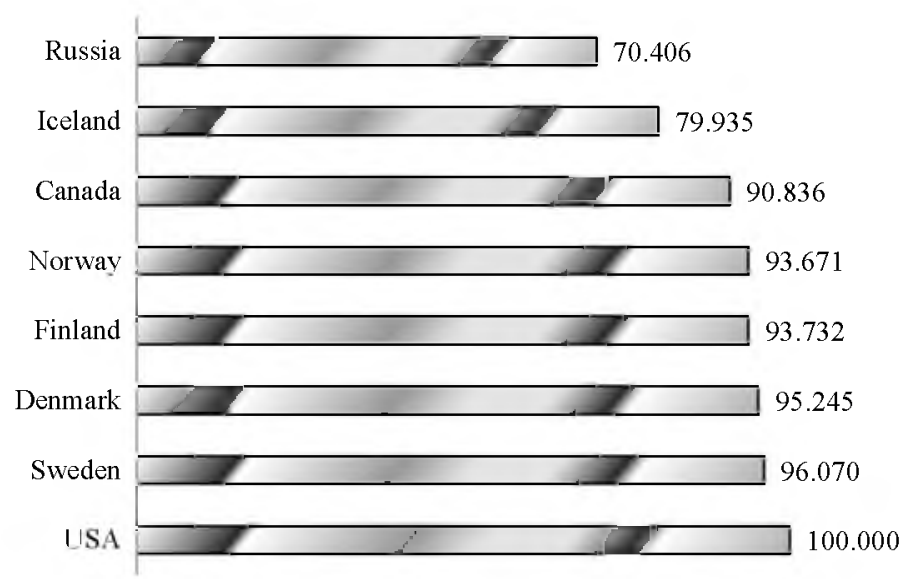

Fig. 80.2 Circumpolar countries' Digital Competitiveness Ranking (the authors' calculations based on the materials of the Internet portal IMD World Digital Competitiveness Ranking [14]) 
As we can see, most circumpolar countries have very high rates of competitiveness in the digital environment.

The diagram shows that the Russian Federation has the lowest rating among the circumpolar countries. Low values were demonstrated for all complex indicators: "Knowledge," "Technologies," "Future Readiness." Even Iceland was ahead of Russia by 9.529 points.

It should be noted that the generalized competitiveness rating in Russia's digital environment is gradually growing. In 2018 , the Russian Federation took 40th place among 63 countries, and in 2019-38th. During the year Russia managed to get ahead of Chile and Thailand. However, Russia's low ratings of in terms of Future Readiness indicator (43 ratings out of 63 in 2018 and 2019) and Technology indicator (51 rankings out of 63 in 2018 and 42 rankings in 2019) are depressing.

Thus, despite the relatively large number of students, Russia is not a competitor in the circumpolar countries' digital environment. According to IMD experts' opinions, the rating of digital development correlates with labor productivity in the country. Even better, productivity correlates with Future Readiness indicator [27].

We believe that the improving Russia's competitiveness in digital environment among other circumpolar countries should be based on the following:

- firstly, to improve current legislation concerning the development of digital environment;

- secondly, to increase government funding for IT branch;

- thirdly, to involve big business, including venture capital for the development of digital environment;

- fourthly, to develop educational process in terms of digital environment requirements;

- fifthly, to involve public administration, population and business of the Arctic territories in the digital environment.

The implementation of these regulations, of course, will not change the extractive nature of the Arctic territories' economy, but can extend its capabilities. Digital technologies not only increase labor productivity and safety, but will improve business ability to adapt to external changes as well.

\subsection{Conclusion}

The study concluded:

1. Arctic territories of the circumpolar countries, as a rule, are rich in minerals and that determines the development of the extractive-type economy. For all that more and more enterprises operate in the digital environment, increasing labor productivity and safety. Therefore, the circumpolar countries run into such fundamental problem as the contradiction between the problem of building 
an innovative, digital economical model and the reality of the extractive-type economy.

2. Having studied the features of economic activity in the Arctic territories of the circumpolar countries, we have revealed several deterrents that inhibit economic development. Objective factors related to the natural, geographical, economic, infrastructure and demographic characteristics, in varying degrees, common to all Arctic areas. Subjective ones are associated with the imperfection of management of the Russian Arctic territories.

3. Our research has shown that the digital product has many subjective prerequisites for the use of digital products in order to solve production and infrastructure problems of the circumpolar countries. Firstly, high added cost of the results of digital products implementation. Secondly, the increasing demands for digital products. Thirdly, the multiplicative effect of the digital product implementation.

4. The analysis shows that the number of students in Russia exceeds some economically developed countries' indices. Among the eight circumpolar countries, Russia takes 4th place in the number of students per 1000 population. This is a favorable but insufficient factor for increasing the country's competitiveness in the digital environment.

5. In the context of the digitalization of the economy, a country's competitiveness in the digital environment is of great importance. The research has shown that, despite the relatively large number of students, Russia is not a competitor in the circumpolar countries' digital environment.

6. We consider that improving Russia's competitiveness in the digital environment among other circumpolar countries should be based on improving legislation concerning the development of digital environment; increasing government funding for the IT branch; involving big business, including venture capital in the development of digital environment; development of the educational process in terms of digital environment requirements; involving public administration, population and business of the Arctic territories in the digital environment.

Acknowledgements This study was supported by the Russian Science Foundation, project No. 19-18-00025.

\section{References}

1. Cockx, L., Francken, N.: Natural resources: a curse on education spending? Energy Policy 92, 394-408 (2016)

2. Gritsenko, D., Efimova, E.: Is there Arctic resource curse? Evid. Russ. Arctic Reg. Resour. Policy 65, 101547 (2020)

3. Marques, A.C., Pires, P.S.: Is there a resource curse phenomenon for natural gas? Evid. Countries Abundant Nat. Gas Resour. Policy 63, 101466 (2019)

4. Bazhutova, E., Skufina, T., Samarina, V.: Entrepreneurial activity of the Russian Arctic Regions: quantitative assessments and management. In: Solovev, D., Savaley, V., Bekker, A., Petukhov, 
V. (eds.) Proceeding of the International Science and Technology Conference "FarEastCon 2019", Smart Innovation, Systems and Technologies, vol. 172, pp. 189-200 (2020)

5. Samarina, V., Korchak, E., Skufina, T., Samarin, A.: Social problems of the Russian Arctic's mono-towns: how to resolve them? TEST Eng. Manage. 82, 3534-3545 (2020)

6. Samarina, V.P., Samarin, A.V., Skufina, T.P., Baranov, S. V.: Social and economic development of Russia's Northern Regions: lessons, trends and decisions the European Proceedings of Social \& Behavioural Sciences EpSBS: GCPMED 2018-International Scientific Conference "Global Challenges and Prospects of the Modern Economic Development”, pp. 388-398 (2018)

7. Savon, D.Y.: Modern approaches to production safety in coal mining. Min. Inform. Anal. Bull. 11, 227-235 (2018)

8. Tambovceva, T., Tereshina, M., Samarina, V.: Green innovations in the regional economy. In: 18th International Scientific Conference «Engineering for Rural Development», 22, 24.05.2019 Jelgava, LATVIA Proceedings, vol. 18, pp. 1832-1839 (2019)

9. Tereshina, M., Miroshnichenko, I., Samarina, V., Halaphyan, A.: Institutional design of regional innovative systems: environmental aspects. In: 19th International Multidisciplinary Scientific GeoConference SGEM 2019, vol. 19, pp. 459-466 (2019)

10. Li, Y., Dai, J., Cui, L.: The impact of digital technologies on economic and environmental performance in the context of industry 4.0: a moderated mediation model. Int. J. Prod. Econ. 229, 107777 (2020)

11. Siedler, C., Langlotz, P., Aurich, J.C.: Identification of interactions between digital technologies in manufacturing systems. Proc. CIRP 81, 115-120 (2019)

12. Elia, G., Margherita, A., Passiante, G.: Digital entrepreneurship ecosystem: how digital technologies and collective intelligence are reshaping the entrepreneurial process. Technol. Forecast. Soc. Chang. 150, 119791 (2019)

13. Number of students in the world and Russia-2018: Infotables.Ru. https://infotables.ru/ statistika/74-demografiya-v-stranakh-mira/826-chislennost-studentov\#hcq=ihLxBYr. Date of access 11 June 2020

14. IMD World Digital Competitiveness Ranking-2019. https:/www.imd.org/wcc/world-com petitiveness-center-rankings/world-digital-competitiveness-rankings-2019/. Date of access 11 June 2020

15. Korchak, E.A., Serova, N.A., Emelyanov, E.E., Yakovchuk, A.A.: Human capital of the Arctic: problems and development prospects. IOP Conf. Ser.: Earth Environ. Sci. 302(1) (2019)

16. Skufina, T., Baranov, S., Samarina, V., Samarin, A.: Natural resources as a factor of socioeconomic development of the Arctic territories: theoretical components of the research problem. IOP Conf. Ser.: Earth Environ. Sci. 302(1) (2019)

17. Skufina, T., Baranov, S., Samarina, V., Samarin, A.: Concerning the connection of geological events and global economic processes: history and the present. In: 19th International Multidisciplinary Scientific GeoConference SGEM 2019, vol. 19, pp. 931-937 (2019)

18. Skufina, T.P., Baranov, S.V., Samarina, V.P.: Dependency between economic development of Russian regions and their level of informatization. Actual Probl. Econ. 7(181), 485-493 (2016)

19. Baranov, S.V., Skufina, T.P., Samarina, V.P., Samarin, A.V.: Specific character and comparative characteristic of informatization of Russia's north-arctic territories. In: The European Proceedings of Social \& Behavioural Sciences EpSBS: GCPMED 2018-International Scientific Conference "Global Challenges and Prospects of the Modern Economic Development", pp. 156-165

20. Rusu-Tanasă, M.: Intellectual capital a strategic factor of socio-economic development of regions and countries. Proc. Econ. Fin. 27, 369-374 (2015)

21. Foroudi, P., Akarsu, T.N., Marvi, R., Balakrishnan, J.: Intellectual evolution of social innovation: a bibliometric analysis and avenues for future research trends. Ind. Mark. Manage. 7, 124-131 (2020)

22. Lai, H., Maskus, E.K., Yang, L.: Intellectual property enforcement, exports and productivity of heterogeneous firms in developing countries: evidence from China. Euro. Econ. Rev. 123, 103373 (2020) 
23. McPhail, K.: Where is the ethical knowledge in the knowledge economy? Power and potential in the emergence of ethical knowledge as a component of intellectual capital. Crit. Perspect. Account. 20(7), 804-822 (2009)

24. Classen, M., Friedli, T.: Value-based marketing and sales of industrial services: a systematic literature review in the age of digital technologies. Proc. CIRP 83, 1-7 (2019)

25. Secundo, G., Ndou, V., del Vecchio, P., de Pascale, G.: Sustainable development, intellectual capital and technology policies: a structured literature review and future research agenda. Technol. Forecast. Soc. Change 153, 119917 (2020)

26. Samarina, V.P., Skufina, T.P., Samarin, A.V.: Russia's North regions as frontier territories: demographic indicators and management features. Euro. Res. Stud. J. XXI(3), 705-716 (2018)

27. Silva, M. do C., Gavião, L.O., Gomes, C.F.S., Lim, G.B.A.: A proposal for the application of multicriteria analysis to rank countries according to innovation using the indicators provided by the World Intellectual Property Organization. RAI Revista de Administração e Inovação 14(3), 188-198 (2017) 